\title{
EFFECTIVENESS OF HYPOGASTRIC ARTERY LIGATION IN OBSTETRIC HEMORRHAGE AND ITS EFFECT ON FERTILITY
}

\author{
Navdar Dogus Uzun', Hasan Terzi ${ }^{2}$, Fulya Uzun ${ }^{1}$ Ahmet Kale ${ }^{3}$ \\ ${ }^{1}$ Department of Obstetrics and Gynecology, Mardin State Hospital, Mardin, Turkey \\ 2 Department of Obstetrics and Gynecology, Health Sciences University Derince Training and Research Hospital, Kocaeli, \\ Turkey. \\ ${ }^{3}$ Department of Obstetrics and Gynecology, Doctor Lufti Kirdar Kartal Training and Research Hospital, Istanbul, Turkey
}

Address for Correspondence: Navdar Dogus Uzun , E-mail: duzun35@hotmail.com Received: 05.05.2021; Accepted: 20.05.2021; Available Online Date: 27.05.2021

@C Copyright 2021 by Dokuz Eylül University, Institute of Health Sciences - Available online at https://dergipark.org.tr/en/pub/jbachs Cite this article as: Uzun ND, Terzi H, Uzun F, Kale A. Effect of hypogastric artery ligation in obstetric hemorrhage and fertilityJ Basic Clin Health Sci 2021; 2: 144-147.

\begin{abstract}
Aim: In this study, we aimed to examine the effectiveness of hypogastric artery ligation method in obstetric hemorrhage and its effects on fertility.

Patients and Methods: Sixty-two patients who underwent bilateral hypogastric artery ligation (HAL) due to obstetric bleeding at Kocaeli Derince Training and Research Hospital between November 1, 2011 and November 1, 2016 were retrospectively evaluated.

Results: In patients with postpartum hemorrhage, bleeding was controlled with HAL in 47 (84\%) of them, while hysterectomy was performed in addition to HAL in $9(16 \%)$ patients. While 17 patients gave consent for bilateral tubal ligation before the operation, none were in the hysterectomy group. Postoperative followup information was obtained for 31 of the remaining 36 patients. It was observed that 7 of the patients had an intrauterine device inserted, 3 gave birth in our center, 18 had regular menstrual periods, and 3 had hysteroscopy due to irregular menstrual periods, which revealed no pathology.

Conclusion: HAL is an important procedure used as the last step in obstetric bleeding, especially in fertility-sparing surgery, and it can be used safely by experienced surgeons. More emphasis should be placed on this surgical method in today's gynecology and obstetrics residency training process.
\end{abstract}

Keywords: Hypogastric artery ligation, obstetric hemorrhage, fertility-sparing surgery

\section{INTRODUCTION}

Obstetric hemorrhages often challenge gynecologists and obstetricians, may cause maternal and / or infant death, and require emergency treatment (1). In addition to uterine artery ligation, utero-ovarian artery ligation, square sutures and B-lynch suture, which are frequently used as first-line treatment in fertility sparing surgery. A less frequently used method, hypogastric artery ligation (HAL), also plays a significant role in control of bleeding $(2,3)$. Today, the incidence of life-threatening bleeding due to placental invasion anomalies is increasing with the climbing cesarean section rates. Therefore, the number of patients indicated for HAL has also escalated (4). It is our opinion that training on this subject should also be increased (5). 
In this study, we retrospectively examined the patients who did not respond to conservative and first-line surgery, after that underwent $\mathrm{HAL}$ in obstetric-induced bleeding and the effectiveness of HAL method and its effects on patients.

\section{MATERIALS AND METHODS}

Sixty-two patients who underwent bilateral hypogastric artery ligation (HAL) due to obstetric hemorrhage at Kocaeli Derince Training and Research Hospital between November 1, 2011 and November 1, 2016 were retrospectively evaluated, after permissions were obtained from the Chief of Department and hospital management. Patients' demographic status, age, gravida, parity, number of abortions, delivery type, gestational week at birth, average birth weight of the newborns, whether consent for bilateral tubal ligation was received prior to the operation, hypogastric artery ligation indication, hysterectomy rates, blood product replacement, whether they had intrauterine devices placed during follow-up, regularity of menstrual cycles and whether pregnancy occurred afterwards were noted.

Information was obtained from patient files and the hospital registry. Patients with known placenta percreta were not included in the study. Follow-up examination of the patients within 3 to 8 years were examined. In patients with suspected placental invasion anomalies during the operation, after the baby was removed, HAL was performed without removing the placenta. In cases of atony, bilateral uterine artery ligation and B-lynch suturing were applied to all patients. In all operations, hypogastric arteries were ligated bilaterally 2 times, $1 \mathrm{~cm}$ apart, 3 $\mathrm{cm}$ distal to the bifurcation point. Two $2 / 0$ free silk sutures were used for ligation. Peritoneal reconstruction was not performed. All HAL cases

Table 1: Demographic data of the patients.

\begin{tabular}{|l|l|l|l|}
\hline & Mean \pm SD & Min & Max \\
\hline Age (year) & $31.04 \pm 4.28$ & 21 & 40 \\
\hline Gravida & $2.95 \pm 1.57$ & 1 & 9 \\
\hline Parity & $1.82 \pm 1.52$ & 0 & 8 \\
\hline Abort & $0.12 \pm 0.38$ & 0 & 2 \\
\hline $\begin{array}{l}\text { Gestational age at } \\
\text { birth (week) }\end{array}$ & $37.2 \pm 2.23$ & 28 & 41 \\
\hline $\begin{array}{l}\text { Fetal weight at birth } \\
\text { (gram) }\end{array}$ & $3020 \pm 767$ & 920 & 4050 \\
\hline
\end{tabular}

SD: Standard deviation

Min: Minimum

Max: Maximum
Table 2: Patients who gave birth after hypogastric artery ligation.

\begin{tabular}{|l|l|l|l|}
\hline $\begin{array}{l}\text { Patient } \\
\text { number }\end{array}$ & $\begin{array}{l}\text { Time } \\
\text { passed } \\
\text { after } \\
\text { HAL } \\
\text { (year) }\end{array}$ & $\begin{array}{l}\text { Gestationa } \\
\text { I age at } \\
\text { birth } \\
\text { (week) }\end{array}$ & $\begin{array}{l}\text { Birth weight } \\
\text { of the } \\
\text { newborn } \\
\text { (gram) }\end{array}$ \\
\hline 1 & 1 & 38 & 3520 \\
\hline 2 & 2 & 37 & 3440 \\
\hline 3 & 2 & 37 & 2780 \\
\hline
\end{tabular}

were performed by two different surgeons. The same number of fresh frozen plasma was transfused with erythrocyte suspension (ES) to the required patients. Scale parameters were described with mean and standard deviations (SD), whereas nominal parameters were described with frequency analysis.

\section{RESULTS}

The mean age of patients who underwent hypogastric artery ligation was $31.04 \pm 4.28$ (mean \pm SD) years, mean gravida was $2.95 \pm 1.57$ (mean \pm SD), and mean parity was $1.82 \pm 1.52$ (mean \pm SD). The mean gestational age at birth was $37.2 \pm 2.23$ (mean \pm SD) weeks. Average birth weight of the newborns was $3020 \pm 767$ grams (mean \pm SD) $($ Table 1).

Before HAL, 56 cases $(90.3 \%)$ were delivered by cesarean section and $6(9.7 \%)$ by vaginal delivery. Among patients who gave birth by cesarean section, $\mathrm{HAL}$ was performed to $48(85.7 \%)$ during the operation, and to $8(14.3 \%)$ by relaparotomy. $\mathrm{HAL}$ indications were uterine atony in 29 patients $(51.8 \%)$, placenta previa (continuous bleeding from the lower uterine segment) in $18(32.1 \%)$, placenta accreta in 5 $(8.9 \%)$, and placenta increta in 4 patients $(7.2 \%)$. While hemorrhage was controlled with $\mathrm{HAL}$ in 47 $(84 \%)$ patients, hysterectomy was performed in addition to HAL in 9 (16\%) patients.

Seventeen patients gave consent for bilateral tubal ligation before the operation, none of which were in the hysterectomy group. The postoperative follow-up information of 24 of the remaining 30 patients was obtained. Four patients had an intrauterine device placed later for birth control, 3 gave birth in our center (Table 2), 10 had regular menstrual cycles, and 2 had undergone hysteroscopy due to irregular menstrual cycles, with no detected pathologies.

Thirty (48\%) patients received ES. The mean units of transfused ES were $3.32 \pm 1.22$ (mean \pm SD), and 10 patients received 4 units. 
The number of cases requiring HAL increased from 3 in 2011-2012 to 27 in 2015-2016 (Table 3).

\section{DISCUSSION}

Obstetric hemorrhage is the leading cause of maternal death, and all pregnant women over 20 weeks of gestation are at risk for postpartum bleeding and sequelae. Although maternal deaths due to obstetric hemorrhages have decreased to a great extent in developed countries, it is still one of the

Table 3: Number of hypogastric artery ligated cases by years.

\begin{tabular}{|l|l|}
\hline Year & Number of cases \\
\hline $2011-2012$ & 3 \\
\hline $2012-2013$ & 7 \\
\hline $2013-2014$ & 10 \\
\hline $2014-2015$ & 15 \\
\hline $2015-2016$ & 27 \\
\hline Total (2011-2016) & 62 \\
\hline
\end{tabular}

major causes of maternal deaths in others (6). Hypogastric artery ligation is one of the last resort treatments in fertility-sparing surgery in major obstetric bleeding.

The number of cases requiring HAL was 3 between 2011-2012 in our center, which increased to 27 between 2015 and 2016. This supports the increased cesarean section rates in our country. Climbing cesarean section rates bring along increased placental invasion and the necessity for HAL in obstetric bleeding $(4,7)$. Although uterine artery ligation, utero-ovarian artery ligation, square sutures and B-lynch suture used in first-line surgery are sufficient in most cases, cases requiring HAL will increase if the cesarean section rates continue to rise and every gynecologist and obstetrician will encounter patients requiring HAL (8). Therefore, we think that more attention should be paid to this surgical method in today's gynecology and obstetrics residency training process.

It is stated in the literature that prophylactic perioperative intravascular balloon occlusion or hypogastric artery embolization can be performed in placental invasion anomalies to prevent pre-operative bleeding, however, this procedure can be performed in a number of university hospitals in our country, it has not been commonly put into practice and does not seem like it will be performed routinely in the near future (9). We predict that the number of cases that will be used as the last step treatment in fertility sparing surgery will increase day by day in gynecology and obstetrics practice.

Another risk factor of obstetric-induced bleeding is multiparity, and the high mean gravida value of 2.95 \pm 1.57 seen among our cases requiring HAL supports this information (10). Therefore, we should evaluate grand multiparity and recurrent cesarean section patients more carefully for preoperative placental invasion anomalies and be alert for postpartum bleeding. We also think that it is useful to reserve blood products for high-risk patients with hemogram values at the lower limit. Among our cases, $48 \%$ required blood product replacements.

The reason necrosis does not occur in the pelvic organs after HAL can be explained by the presence of five important collateral arteries, which include those between the peripheral and central parts of the hypogastric artery, between the peripheral and aortic branches, between the uterine artery and the subcutaneous abdominal artery, and the aorticoovarian and reno-ovarian collaterals (11). The facts that some of these patients gave 3 live births and the remaining patients having regular menstrual cycles support the functions of these anatomic collaterals. HAL is an important procedure used as the last step treatment in obstetric bleeding, especially in fertility sparing surgery, and can be used safely by experienced surgeons. It is our opinion that more importance should be given to this surgical method in today's gynecology and obstetrics residency training process.

Conflict of Interest: The authors declare that they have no competing interest.

Peer-review: Externally peer-reviewed.

\section{REFERENCES}

1. McLintock $\mathrm{C}$, James $\mathrm{AH}$. Obstetric hemorrhage. J Thromb Haemost. 2011 Aug;9(8):1441-51.

2. Sziller I, Hupuczi P, Papp Z. Hypogastric artery ligation for severe hemorrhage in obstetric patients. J Perinat Med. 2007;35(3):187-92.

3. Kayem G, Kurinczuk JJ, Alfirevic Z, Spark P, Brocklehurst $P$, Knight $M$, et al. Specific secondline therapies for postpartum haemorrhage: $A$ national cohort study. BJOG. 2011;118:856-64.

4. Demirbaş $M$, Karabel $M$, İnci $M$. Türkiye'de ve Dünya'da Değişen Sezaryen Sıklığı ve Olası Nedenleri. Sakarya Tıp Dergisi. 2018; 7(4): 158163.

5. Lumbreras-Marquez Ml, Campos-Zamora M, Ramirez-De Avila AL, Soto-Galindo JC, OlivasChavez JC, Tecayehuatl-Delgado G, HernandezRayon YI, Ramirez-Calvo JA, Farber MK. 
Training for the surgical management of postpartum hemorrhage: a multicenter survey of resident physicians. J Matern Fetal Neonatal Med. 2019:1-7.

6. WHO. Reducing the Global Burden: Postpartum Haemorrhage. Making Pregnancy Safer. 2007.

7. Thia EWH, Lee SL, Tan HK, Tan LK. Ultrasonographicalfeatures of morbidly-adherent placentas. Singapore Med J2007; 48(9): 802.

8. Trikha A, Singh PM. Management of major obstetric haemorrhage. Indian J Anaesth. 2018;62(9):698-703.

9. Chou MM. Prenatal diagnosis and perinatal management ofplacenta previa accreata: Part, present and future. TaiwaneseJ Obstet Gynecol 2004; 43(2): 64- 71.

10. McLintock $C$, James $A H$. Obstetric hemorrhage. J Thromb Haemost. 2011 Aug;9(8):1441-51. doi: 10.1111/j.1538-7836.2011.04398.x.

11. Brătilă E, Brătilă C. $P$, Coroleucă C. B, Coroleucă C. A. Collateral circulation in the female pelvis and the extrauterine anastomosis system. Rom J Anat. 2015; 14(2): 223-227 